\title{
Research
}

\section{Qualitative study of the meaning of personal care in general practice}

\author{
Carolyn Tarrant, Kate Windridge, Mary Boulton, Richard Baker, George Freeman,
}

\begin{abstract}
Objectives To explore patients' perceptions of the features of personal care and how far these are shared by healthcare providers; whether a continuing relationship between a health professional and a patient is essential for personal care; and the circumstances in which a continuing relationship is important.

Design Qualitative analysis of semistructured interviews using the "framework" approach.

Setting Six general practices in Leicestershire. Participants 40 patients aged $\geq 18$ years, 13 general practitioners, 10 practice and community nurses, and six practice administrative staff, recruited through participating practices.

Results Patients' and healthcare providers' accounts cited human communication, individualised treatment or management, and whole person care as features of personal care. Personal care was described in three different contexts-a continuing relationship, a single consultation, and from the practice as a whole. The extent to which a continuing relationship was important for personal care was determined by the reason for consulting, as well as patients' consulting history and lifestyle.

Conclusions Patients, general practitioners, primary care nurses, and administrative staff hold similar views on the meaning of personal care, despite differences of emphasis reflecting their different roles. Personal care is promoted by but not always dependent on a continuing provider-patient relationship; human communication and individualised care emerged as important in making care personal whatever the context. Most respondents valued relationships in primary care and had clear ideas about when care in the context of a relationship was most valuable.
\end{abstract}

\section{Introduction}

Personal care is recognised as a central role of general practitioners (GPs). ${ }^{1-5}$ It is seen as a feature of a continuing relationship between a GP and a patient and as being linked to a GP's increasing knowledge about the patient. Hence, continuity of care (the extent to which patients are able to see the same doctor or nurse over time $)^{6}$ has been suggested as important in promoting personal care. $^{7}$
However, recent and forthcoming changes in the organisation of primary care in the NHS and the role of GPs-which are intended to improve some aspects of care-may reduce continuity of care, and this in turn may threaten personal care. For example, primary healthcare teams have been growing in size, ${ }^{8}$ and patients have greater choice of provider, including access to the telephone helpline NHS Direct and in some places walk-in centres. Government policy for England states that patients should be able to get an appointment with a GP within 48 hours, ${ }^{9}$ and a report on the future of health services predicts further changes, including the provision of much routine care by nurses and assistants, allowing GPs to become more specialised. $^{10}$ The new draft GP contract proposes practice lists rather than personal lists of registered patients. ${ }^{11}$

Despite these changes, it is not clear whether concern about personal care is well founded or what action can be taken in response. The nature of personal care has been little studied; previous research has focused on the doctor-patient relationship, ${ }^{12}{ }^{13}$ but there may be other ways of making care personal.

We report a qualitative study of the nature of personal care. We aimed to explore (a) patients' perceptions of the features of personal care and how far these are shared by healthcare providers, (b) whether a continuing provider-patient relationship is essential for care to be personal, and (c) the circumstances under which a continuing relationship is important.

\section{Methods}

Six general practices in Leicestershire took part (12 had been approached), selected to ensure diversity. Practices varied in size (one singlehanded, two with two to four partners, three with five or more partners), location (two inner city, three suburban or urban, and one rural), and patients (in terms of socioeconomic and ethnic group characteristics). Each participating practice drew a quota sample of patients aged 18 and over from their practice list, excluding patients deemed inappropriate-for example, those likely to be distressed by being approached to take part in the study. Each practice sent patients an information sheet and a letter inviting them to return a form to the researchers giving consent to participate. Recruitment continued until sampling frame requirements were met for diver-
Clinical

Governance

Research and

Development Unit,

Department of

General Practice

and Primary Health

Care, University of

Leicester, Leicester

LE5 4PW

Carolyn Tarrant

research associate

Kate Windridge

research fellow

Richard Baker

professor of quality in health care

School of Social Sciences and Law, Oxford Brookes University, Oxford OX3 0BP

Mary Boulton professor of sociology

Centre for Primary Care and Social Medicine, Imperial College London, London W6 8RP

George Freeman

professor of general practice

Correspondence to: C Tarrant

ccp3@le.ac.uk

bmj.com 2003;326:1310 
Table 1 Characteristics of participating patients $(n=40)$.

\begin{tabular}{lc} 
Characteristic & No of patients \\
\hline Men/women & $15 / 25$ \\
\hline Age (years): & 5 \\
\hline $18-20$ & 11 \\
\hline $21-40$ & 12 \\
\hline $41-60$ & 12 \\
\hline$\geq 61$ & \\
\hline Ethnicity: & 29 \\
\hline White & 9 \\
\hline Asian & 2 \\
\hline Afro-Caribbean & 15 \\
\hline Health problems: & 25 \\
\hline None or acute & 14 \\
\hline Chronic or multiple & 8 \\
\hline Location: & 9 \\
\hline Village or rural & 9 \\
\hline Small town & \\
\hline Suburban & 11 \\
\hline Inner city & 5 \\
\hline Employment: & 12 \\
\hline Full time & 4 \\
\hline Part time & 3 \\
\hline Retired & 27 \\
\hline Unpaid work (eg caring for family) & 13 \\
\hline Unable to work (due to health) & \\
\hline Full time education & \\
\hline Not known & \\
\hline Carer? & \\
\hline Yes & \\
\hline No & \\
\hline & \\
\hline
\end{tabular}

sity in age, sex, ethnicity, frequency of attendance, and health status. In each practice we also interviewed one to four GPs, nurses, and receptionists.

We used a narrative based approach in interviews, with a topic guide specifying open ended exploration of the meaning, value, and priority given to personal care, and of factors that facilitated or inhibited it, in the context of each respondent's experience. KW and CT did the interviews, which lasted 30-90 minutes; all but

Table 2 Characteristics of practice staff (13 general practitioners, 10 nurses, 6 other staff). Values are numbers of staff

\begin{tabular}{llll} 
Staff & GPs & Nurses & Other staff \\
\hline Men/women & $8 / 5$ & $1 / 9$ & $0 / 6$ \\
\hline Age (years): & 3 & 1 & 1 \\
\hline$<30$ & 2 & 7 & 4 \\
\hline $30-50$ & 8 & 2 & 1 \\
\hline$>50$ & & & 5 \\
\hline Ethnicity: & 9 & 9 & 1 \\
\hline White & 4 & 1 & - \\
\hline Asian & & & - \\
\hline No of years since GP registration: & 2 & - & - \\
\hline Registrar & 1 & - & - \\
\hline$<10$ & 2 & - & - \\
\hline $10-20$ & 8 & - & - \\
\hline$>20$ & & & - \\
\hline No of years in current practice: & 7 & - & - \\
\hline$<10$ & 4 & - & 5 \\
\hline $10-20$ & 2 & - & 1 \\
\hline$>20$ & & 7 & - \\
\hline Role: & - & - & \\
\hline Practice nurse & - & - & - \\
\hline District or community nurse & - & & \\
\hline Receptionist & & & \\
\hline Assistant practice manager & & & \\
\hline
\end{tabular}

two interviews were audiotaped and transcribed verbatim. One GP and one patient requested note taking only. Both interviewers kept reflective diaries, providing an audit trail relating the content and context of each interview to themes emerging during concurrent analysis.

Analysis of the data followed the "framework" approach. ${ }^{14}$ CT and KW developed descriptive codes from independent repeated readings of transcripts, then identified emerging themes on the basis of initial indexing, hierarchical grouping of codes, and discussion of individual transcripts. Themes were validated by discussion among all authors after independent reading of a sample of transcripts.

At this stage of the analysis, three focus groups of patients (28 people) and four of health professionals (18 GPs, eight practice or community nurses, and eight administrative staff) were held to test the validity of initial interpretations. We recruited participants from the participating practices and from a local support network of singlehanded practices (we had had only one singlehanded practitioner in the initial sample and wanted more views from this group). Participants discussed statements relating to identified themes and were asked to give examples of any opposing beliefs. Subsequently all the original interviewees were invited to provide postal feedback on an interim report of the findings.

This process resulted in preliminary themes being revised and developed into thematic frameworks. We drew up charts for each interviewee, summarising the meanings of personal care and the contexts within which it featured.

\section{Results}

We held interviews with 40 patients in their homes and 13 GPs, 10 practice and community nurses, and six practice administrative staff on practice premises (tables 1 and 2).

\section{Features of personal care}

We identified three main features of personal care from interviewees' accounts: human communication, individualised or tailored care, and "whole person" or holistic care.

\section{Human communication}

Human communication was the most prominent theme in patients' accounts of their experiences of personal care and was also central in accounts of providers (GPs, nurses, and administrative staff). This theme encompassed good interpersonal or communication skills on the part of the provider, evidence of empathy, and the perception that providers listened and "had time" for the patient. Social talk and appropriate use of humour were also described (box 1).

\section{Individualised or tailored care}

Individualised diagnosis, treatment, and management was also an important theme, although patients were less likely than providers to explicitly describe personal care in these terms. GPs and nurses talked about tailoring their management of conditions and their information giving, and reception and administrative 


\section{Box 1: Human communication}

\section{Patients}

"Dr O helped me a lot, you see. I find it easier to talk to him 'cause he listens really, really well. He takes his time ... Yeah, he likes to listen" (patient 28)

"He made you feel relaxed ... he calls you by first name, you felt as if you could talk-and you could have a laugh with him as well, you know, which I think is really good" (patient 39 )

\section{Providers}

"A lot of it is just listening to them; it is purely listening, knowing that they know you are there for them and understand" (GP 3)

"You look up and smile-you've got to try to look up and smile, even if you know that this patient drives you mad ... I just try and think what I would expect from my practice nurse ... how would I want to be greeted when I walk in the door ... The same when they're going out. I might be tapping on the computer, but I will always make sure that I look at them and say 'bye, see you whenever"' (nurse 7)

"If a patient comes to you, and they have a lot of problems at home, they have a lot of problems with their health, to be able to talk to somebody who can listen to them, and as I say, have some empathy with them, counts a lot" (receptionist 4)

\section{Box 2: Individualised or tailored care}

\section{Patients}

"As I said earlier about being personal, so you felt like you are treated as an individual and not just as statistics: as an individual and not generally-'oh well you've had what Joe has had down the road, you know, you've got this, so you've got to be treated in this way.' I think it goes a lot deeper than that" (patient 25)

"He's usually got half the prescription wrote out before you even walk in ... like you're on a conveyor belt system" (patient 38, about lack of personal care)

\section{Providers}

"It's about ... knowing what [patients'] expectations are ... tailoring the treatment to the person. You can't treat everybody just the same, because they are all different... Some people just need more time, more explanation (GP 1)

"You can have two people with exactly the same diagnosis, same condition, but totally different ways of looking after them because of the actual, you know, their lifestyle, the environment that they're living within, and you've got to adapt to that really" (nurse 2) "[You need to] say something jolly like 'good morning, how are you?' or if you know that it's a festival of somebody's religion, if you just say 'happy Diwali.' I mean it personalises the whole thing, doesn't it? I mean at the moment we're fasting, I know all the Muslims are fasting, so I'll say 'happy Ramadan,' and they'll smile and say 'and to you as well'" (receptionist 5)

staff talked about tailoring their social talk, as specific ways of providing personal care (box 2).

\section{"Whole person" or holistic care}

Many patients' accounts centred on dealing with the "whole person" in the context of their life and illness, rather than just treating the presenting illness. Patients often referred to the importance of professionals knowing about them and their family history. This theme also featured strongly in health professionals' accounts. It was particularly salient for nurses, who described themselves as specialists in this respect. Receptionists also emphasised the need to understand the life context surrounding a patient's behaviour (box 3).

\section{Differences among participants' accounts}

All accounts described personal care as treating someone as an individual person rather than just another patient. Patients tended to focus on the experience of receiving personal care, and human communication was central to this. GPs, nurses, and practice staff described how they tried to provide personal care-through individual, tailored treatment and by treating the whole person-although they also recognised the role of human communication. There were also differences in emphasis among the different professional groups. Nurses often defined personal care as holistic care and described this as fundamental to their role. GPs tended to focus on the importance of a continued relationship in developing personal knowledge and of maintaining consistency and effectiveness of treatment. Receptionists were particularly keen to ensure that the practice seemed friendly.

\section{Is a continuing relationship always necessary for personal care?}

Personal care was usually described in the context of a continuing provider-patient relationship. However, both patients and providers described personal care in two other contexts: in a single encounter with an unfamiliar provider and in the practice as a whole.

\section{Box 3: "Whole person" or holistic care}

\section{Patients}

"I do find that if you're with the same doctor ... they know what's wrong, they've followed you through your life, they know about your family. My doctor will say to me 'your mother's got high blood pressure-we'll have to check that next time you come' or whatever, and I like that because they can see patterns in people's lives" (patient 31)

\section{Providers}

"You may actually know other members of the family, you know where they live, what they do, and you've seen them when they're well, when they're unwell .. that broader understanding of a patient and where they're coming from is in part personal care' (GP 6) 'Well it's part of the nursing philosophy, is the holistic approach ... The doctors are very much instant diagnosis people and not so much looking at the whole background. Looking at the whole background-the person's life, what impressions it's making on their life, especially chronic disease-that's a huge part of it" (nurse 3)

"We have drug addicts, we have alcoholics, people who are very, very depressed ... some people find it very difficult to be compassionate towards someone who's standing there at the counter saying 'I want my drugs now' ... but people take drugs for different reasons, you know, they become involved for different reasons" (receptionist 4) 


\section{Box 4: The continuing relationship}

\section{Patients}

"I think a one to one relationship obviously makes the care personal ... and really that's established over the years" (patient 1 )

"As soon as you go in you are completely relaxed with him because you know that you're not a number, and you're not a patient once you're in his surgery door, you are that person ... he knows you as" (patient 40)

\section{Providers}

"As I understand it, personal care is given to the same patient by the same doctor all the time, who knows that patient very well from his previous problems" (GP 1)

"Seeing [patients] on an ongoing basis ... To me that makes it more personal because you are building up a relationship of confidentiality and trust" (nurse 2)

"We have got a lot of new staff recently. Some of the patients that have known me for years, they will ask for me if they ring up and they will say 'oh I've asked for you because I know you'” [Interviewer asks "What do you think they get out of it?"] "Personal service I think, because they know if they ask me, because I know them, they'll get a straight answer back, whereas if they go to somebody that doesn't know them they perhaps have to ask more questions to get what they want" (receptionist 2)

\section{The continuing relationship}

A continuing relationship was central to many accounts of personal care (box 4). The patient could become familiar with the provider, and the provider had the opportunity to develop personal knowledge of the patient-for example, his or her illness, social circumstances, or family history-which helped them to provide individualised and holistic care. Personal care in a relationship was valued for fostering trust and confidence, putting the patient at ease, facilitating open communication, and promoting better long term management.

However, not all continuing relationships between patients and health professionals were described as including personal care. Care was not seen as personal when previous consultations were not referred back to or built on, despite repeated encounters, or when patients felt they were not being responded to in an appropriate or human way.

\section{The brief encounter}

Although continuing relationships were seen as promoting personal care, some patients reported receiving personal care in a single consultation with an unfamiliar provider. Patients' accounts of these "brief encounters" emphasised good human communication skills and empathy (box 5).

Although health professionals believed that personal care in a brief encounter was possible, GPs were more reluctant than nurses to describe personal care in these terms. Providers described communication skills and responsiveness to patients' feelings as important in this context; having the time to use these skills was crucial.

Personal care in a brief encounter was seen as helping to put patients at ease and making it easier for patients to discuss concerns and ask questions. In some cases patients saw such care as a motivating factor in developing a continuing relationship and sought to consult the same health professional for future consultations.

\section{Practice level personal care}

Many patients felt that the wider practice team, and receptionists in particular, were as important as individual health professionals in making care personal (box 6). This was reflected in receptionists accounts, although some felt this role could be difficult, particularly when under pressure.

GPs were relatively unlikely to describe "practice level" personal care unprompted, but both nurses and receptionists felt that good communication within the practice team promoted personal care (box 6). This was viewed as particularly important for patients with complex or chronic problems. Practice level personal care seemed to be easier to achieve when all staff felt

\section{Box 5: The brief encounter}

Patients

"He was concerned, he'd got a lovely manner about him, and ... it wasn't a case of 'I'll pull you in, examine you, and push you out'-he talked, spoke all the time to me... and that made you feel more at ease" (patient 22)

\section{Providers}

"I don't think (personal care) happens in a single consultation, I think it happens over a number of consultations" [Interviewer asks "So is it impossible for care to be personal where you're just seeing someone in a single consultation?"] "It's not impossible. You can see one patient just once and they can go away feeling happy ... so yes there is an element of personal care in that consultation" (GP 7)

"I think you can [make care personal] by talking to them and finding out how they feel about treatment and what they're expecting from you" (nurse 1)

"When we're very busy it's probably not personal hardly at all ... I think it's more to do with time than anything else really" (nurse 4)

\section{Box 6: Practice level personal care}

Patients

"This new practice ... it's a far more friendly atmosphere and it's far more personal ... I feel comfortable going in there ... they remember you, although I don't see them perhaps that often" (patient 15)

"It's gotta start from when you first walk through the door ... OK, the receptionist shouldn't know any medical backgrounds but name-wise it's brilliant. You know, it puts you at ease" (patient 39)

Providers

"I think it's quite important to have a bit of compassion .... the reception is the first step towards the doctor and ... where you get a complete blank wall as soon as you walk in, that is very off-putting ... Then when they go in to see the doctor they can have this defensive attitude with them" (receptionist 4)

"The basis of trying to provide personal care is trying to communicate what this patient's needs are to other people that are going to see this patient"(nurse 8) 
Box 7: When is a continuing relationship important?

\section{Reason for consulting}

"If I'd sprained my wrist I wouldn't care who I saw; but if it was something ongoing... I would want to see my own GP, or if it was something of a more intimate nature, I wouldn't want to see any GP and I would wait to see him" (patient 18)

"Some of the men ... if they've needed personal dressings, we have handed them on to the district nurse rather than do it ourselves, because she is that much more removed from the practice" (nurse 1)

\section{Consulting history}

"I try to keep to the one doctor ... because if you keep going to different doctors how do they know you? I mean, as I said, I've been with this one so long that he knows me quite well. Yes I like to see Dr X"

[nterviewer asks "So would you generally wait for him, or are there times when you would see someone else?"] "Unless it was something very urgent, yes I would wait" (patient 36)

Social context and lifestyle

"That's how it's been in the villages. We have a personal relationship with our vicar and the doctor" (patient 1)

involved in the practice, shared common goals, and had developed informal ways of communicating about patients.

\section{Under what circumstances is a continuing relationship important?}

GPs, nurses, receptionists, and patients agreed about when a continuing relationship was important in making care personal. Their accounts suggested that the need for a continuing relationship depended primarily on three things: the patient's reason for consulting, the consulting history, and the social context and lifestyle of the patient.

\section{Reason for consulting}

When a patient's reason for consulting involved an acute, easily resolved problem, most patients and health professionals felt that care could be personal in a brief encounter. However, if a problem was long term or complex or if it involved emotional concerns, a long term relationship was often seen as essential. Under these conditions interviewees felt that a health professional needed to be familiar with the patient's background and concerns, and patients were prepared to wait for an appointment to get this level of personal care (box 7).

In some circumstances personal care in a continuing relationship was seen as undesirable, particularly when dealing with an issue that might disrupt an otherwise successful relationship or when care from a familiar health professional might cause embarrassment. Health professionals acknowledged needing to be sensitive to this (box 7).

\section{Consulting history}

Patients who had already built a relationship with a provider through past consultations emphasised the importance of a continuing relationship in ensuring that the care they received was personal (box 7).
Patients who consulted several different health professionals-for example, in a large practice or because of the nature of their illness-were more likely to feel that care could be personal in other contexts.

\section{Social context and lifestyle}

Patients who saw themselves as busy or who had chaotic lives were more likely to value quick access and were more likely to feel that they could get personal care without a continuing relationship. Some patients felt that continuing relationships were central to their way of life and were less likely to describe personal care in other contexts (box 7).

Healthcare providers were pragmatic in their view of whether a continuing relationship was essential for personal care. GPs usually described continuing relationships as necessary for personal care, but if they had many patients with busy or chaotic lifestyles, they were likely to describe meeting patients' access needs as being part of making care personal.

\section{Discussion}

The findings show that personal care involves human communication with the patient, individualised or tailored treatment, and care of the whole person. A continuing provider-patient relationship was seen as promoting the development of personal care, ${ }^{7}$ but care could also sometimes be personal in a single consultation with an unfamiliar professional, particularly if a problem was acute or easily resolved. Personal care in the context of a relationship was important if problems were complex or emotional, as this enabled the health professional to become familiar with the patient's story $^{15}$; this accumulated understanding of the patient was seen by provider and patient as important in appropriate management. In contrast, patients with potentially embarrassing problems sometimes (but not always) preferred personal care outside a relationship. Finally, personal care could be a feature of the practice as a whole; interactions between patients and members of the wider practice team and communication within the practice team were described as contributing to personal care.

Patients, GPs, practice and community nurses, and administrative staff held similar views on the core meaning of personal care, despite differences of emphasis reflecting their different roles. GPs in particular emphasised the value of a continuing relationship in making care personal; this may reflect both their acceptance of traditional definitions of personal care and their specific professional values. However, patients do not always regard an ongoing relationship as essential to personal care.

The study involved a limited number of patients and health professionals from a limited number of practices in one area in the United Kingdom, and the results reflect the views of this group. However, we interviewed participants with diverse characteristics and included the views not only of patients and GPs but also of practice nurses and receptionists, who have generally been excluded from previous studies. Experiences of and beliefs about personal care were explored in depth. Despite the diversity of the sample, common features were identified in descriptions of what made care personal. 
The features central to personal care are similar to those identified by Arborelius and Bremberg. ${ }^{13}$ However, this study explored the wider context of primary care rather than focusing solely on the relationship between GP and patient and has shown that personal care is not limited to the context of the GP-patient relationship.

Other research has shown that a personal relationship is valued by patients and GPs, when patients have serious, psychological, or family problems. ${ }^{16}$ Our findings also show that personal care in the context of a relationship is particularly valuable to patients who have complex or ongoing problems or problems with a high subjective impact. We are now studying the circumstances under which a continuing relationship is given priority by patients.

We found that patients and health professionals alike emphasise the value of personal care. This suggests that primary care trusts, practices, and individual professionals should ensure that personal care is maintained despite changes in primary care delivery. This means promoting other routes to personal care in addition to providing opportunities for continuing relationships.

Good communication featured as an essential component of personal care, especially from the recipients' viewpoint. If GPs and other practice members wish to focus on developing personal care, developing communication skills would be an important step. ${ }^{18}$ Additionally, managers should make sure staff have the time and support to use communication skills effectively. The study has highlighted that receptionists play an important role in patients' experiences of personal care; receptionists' contribution to practice level personal care should be recognised and supported by practices. The organisation and culture of a practice were also seen as having an influence on personal care, and research on this issue and on the role of receptionists in personal care would be valuable. $^{19}$

\section{Conclusion}

Our findings suggest that personal care is promoted by, but not always dependent on, an ongoing providerpatient relationship. Human communication and individualised care are critical in making care personal whatever the context. Most respondents valued relationships with GPs and other providers in primary care, expected these relationships to evolve dynamically, and had clear ideas about when care in the context of a relationship was most valuable. Changes in policy and practice in primary care could threaten personal care if they make it more difficult for patients to get care in the context of a relationship when they need it. Consequently practices should have systems that enable patients to consult in the context of a continuing relationship whenever they wish.

We thank the practices that helped us with the study, and the patients, GPs, nurses, and practice staff who took part in interviews or focus groups. We also thank Raj Gill and Vicki Cluley for their help in transcribing tapes.

Contributors: RB, MB, and GF designed the study protocol. KW and CT conducted the interviews. All authors helped in the analysis and interpretation of the interview data and in writing the paper. CT will act as guarantor for the paper.

\section{What is already known on this topic}

Personal care has traditionally been seen as a feature of an ongoing relationship between general practitioner and patient

However, patients' and primary care staff's views on the meaning of personal care have not been explored

\section{What this study adds}

General practice patients and providers (GPs, primary care nurses, and administrative staff) hold similar views on the meaning of personal care

They cite human communication and individualised care as important in making care personal

Personal care is promoted by, but not always dependent on, an ongoing relationship between patient and provider

The whole practice team has a role in making care personal

Funding: Trent NHS Executive's policy and practice R\&D programme. The guarantor accepts full responsibility for the conduct of the study, had access to the data, and controlled the decision to publish.

Competing interests: None declared.

Ethical approval: Leicestershire research ethics committee approved the study

1 Royal College of General Practitioners. The future medical practitioner learning and teaching. London: British Medical Journal, 1979.

2 Royal College of General Practitioners. The nature of general medical pracRoyal College of General

tice. London: RCGP, 1996.
General Medical Services Committee. Care services: taking the initiative. London: BMA, 1996.

4 Secretary of State for Health. Choice and opportunity. Primary care: the future. London: Department of Health, 1996.

Wonca Europe. The European definition of general practice/family medicine. Barcelona: WHO Europe Office, 2002.

6 Freeman G, Shepperd S, Robinson I, Ehrich K, Richards S, Pittman P. Continuity of care: report of a scoping exercise for the SDO programme of NHS $R \mathcal{E} D$ D. London: NHS Executive, 2000.

7 Gray DJP. The key to personal care. J R Coll Gen Pract 1979;29:666-78.

8 Baker R. Will the future GP remain a personal doctor? Br J Gen Pract 1997;47:831-4.

9 Secretary of State for Health. The NHS plan. London: Stationery Office, 2000.

10 Wanless D. Securing our future health: taking a long term view. London: HM Treasury, 2001

11 General Practioners Committee. Your contract, your future. London: BMA, 2002.

2 Fitton F, Acheson, HWK. The doctor/patient relationship: a study in general practice. London: HMSO, 1979.

13 Arborelius E, Bremberg S. What does a human relationship with the doctor mean? Scan J Prim Health Care 1992;10:163-9.

14 Richie J, Spencer L. Qualitative data analysis for applied policy research. In: Bryman A, Burgess R, eds. Analysing qualitative data. London: Routledge, 1994.

15 Barry CA, Stevenson FA, Britten N, Barber N, Bradley CP. Giving voice to the lifeworld. More humane, more effective medical care? A qualitative study of doctor-patient communication in general practice. Soc Sci Med 2001;53:487-505.

16 Schers H, Webster S, van den Hoogen H, Avery A, Grol R, van den Bosch W. Continuity of care in general practice: a survey of patients' views. $\mathrm{Br}$ Gen Pract 2002;52:459-62.

17 Kearley KE, Freeman GK, Heath A. An exploration of the value of the personal doctor-patient relationship. Br J Gen Pract 2001;51:712-8.

18 Maguire P, Pitceathly C. Key communication skills and how to acquire them. BMJ 2002;325:697-700.

19 Eisner M, Britten N. What do general practice receptionists think and feel about their work? BrJ Gen Pract 1999;49:103-6.

(Accepted 20 March 2003) 


\title{
Patient's response to the research
}

\author{
Janey Antoniou
}

Janey Antoniou, a former scientist with a chronic health condition, comments on "He treats you as a person"

I'm a mental health service user with a background in scientific research and the misfortune to have a diagnosis of schizophrenia. I read this piece of research with interest, as personal care from general practitioners is very important to mental health service users who are trying to survive in the community. This is especially true when senior house officers and registrars in the psychiatric system leave at the end of their six month rotation and there is no long term continuity of care for a lot of people. The GP is part of the psychiatric care programme approach, whether he or she likes it or not.

As a former scientist I'm used to reading the $B M J$ and enjoy having data and references present in a paper so I can make up my own mind on the validity of the conclusions. However, given that this issue is aimed at patients, I found this study easy to read and understand. Although there was a small amount of jargon (focus groups, primary care trusts, practice level care), it was written in a style that I think would be readable by most people with a reasonable command of English. I particularly liked the direct quotes from interviewees because they underlined what the authors were saying in the text, but in accessible language. I wonder what provision was made in the questionnaires and focus groups for people with limited English, especially since the study was carried out in an area with a large ethnic population. Do people from other cultures want the same from a GP?

On the whole I agree with the results about the GPs and nurses in this study. I have a chronic illness that has quite a high emotional content, and I would much rather see the same person all the time for this. For acute and painful things I would also be pragmatic and see the first person with whom I could get an appointment. I was, however, a little perplexed by the importance given to receptionists by patients and the medical staff, as I have always seen them as people whose job is to restrict my access to the GP!

The main finding - that patients want to be seen as whole human beings with individual needs-seems so obvious that the only thing that surprises me is that managers and policy makers would think of moving away from this. Perhaps it is a good thing this study has been done, and I hope the people who make the decisions about such things have a chance to read it. Competing interests: None declared.

\section{Patient's response to the research}

\section{David Wilkins}

David Wilkins, policy officer with the Men's Health Forum (www.menshealthforum.org.uk), responds to "He treats you as a person not just a number"

Since "personal care" is ostensibly at the heart of primary care provision, it seems extraordinary that the concept remains-as the authors here rightly say-little studied. This research suggests that there is some important common ground between patients and healthcare providers but that perceptions nevertheless differ according to viewpoint. One of the more obvious factors that might have a bearing on the nature of the experience for patient and professional alike is the gender of the participants in that experience. Bald statistics tell us that men are significantly less likely to visit their GP than women, and anecdotal evidence suggests that they are rather more likely to present at a later stage in the development of disease. It seems likely that this state of affairs contributes to the continuing poor state of male health. Beyond speculation, however, we know next to nothing about why this should be.

Much of what we learn from this study has the ring of truth in the light of what we have learned at the Men's Health Forum about men's expectations, attitudes, and behaviour. Responses to men's needs in primary care have in the past often centred on structural issues. Access may remain a problem for men in full time work, for example-though whether solving access problems is a significant contribution to making care more "personal," as suggested by some of the GPs here, is a point that might bear further examination.

Our experience suggests that a rooted reluctance to accept personal vulnerability may disturb the balance of good judgment for many men. It should go without saying, too, that unhelpful presumptions about how the sexes might, or should, respond to illness and injury are unlikely to be the sole prerogative of patients. The assertion here that "embarrassing problems" may lead to a preference for a service provided outside an established personal relationship directs us gently towards some extremely interesting questions about the nature of the relationship between professional and patient. Embarrassment is not the only form of personal exposure that patients must allow themselves to suffer. Do we currently know how to create environments that allow men to be comfortable in expressing their fears and concerns?

There is much in this study that is useful (not least, incidentally, its accessible and readable style). More sensitive service provision is by no means the only
Edgware HA8 6LJ Janey Antoniou mental health trainer WC1H 9HR David Wilkins policy officer

david.wilkins@ menshealthformum org.uk 
route to the improvement of male health, but it is an important one. Any work that enhances our understanding of good primary care has the potential to benefit men. For those interested in the impact of male gender on health, though, the central questions remain largely unasked and certainly unanswered.

Competing interests: None declared. 